\title{
Coulisses
}

Revue de théâtre

\section{Les Portes sous-marines. Invitation au voyage au centre de la... mer}

Christian Bozon, Valérie Goy et Rédaction

\section{(2) OpenEdition}

1 Journals

Édition électronique

URL : http://journals.openedition.org/coulisses/1657

DOI : $10.4000 /$ coulisses. 1657

ISSN : 2546-9460

Éditeur

Presses universitaires de Franche-Comté

\section{Édition imprimée}

Date de publication : 1 février 1991

Pagination : 62-64

ISSN : 1150-594X

\section{Référence électronique}

Christian Bozon, Valérie Goy et Rédaction, « Les Portes sous-marines. Invitation au voyage au centre de la... mer », Coulisses [En ligne], 3 | Hiver 1991, mis en ligne le 04 juillet 2017, consulté le 21 octobre 2019. URL : http://journals.openedition.org/coulisses/1657; DOI : 10.4000/coulisses. 1657

Ce document a été généré automatiquement le 21 octobre 2019.

Coulisses 


\title{
Les Portes sous-marines. Invitation au voyage au centre de la... mer
}

\author{
Christian Bozon, Valérie Goy et Rédaction
}

Du 28 mai au 23 juin 1990 des Portes sous-marines se sont ouvertes à l'espace Planoise de Besançon, pour les nombreux visiteurs, qui ont pu redécouvrir ce milieu, d'une manière tout à fait originale puisqu'excluant son principal élément - l'eau - figurée par des matières plastiques colorées et transparentes.

2 Tout au long d'un parcours jalonné de poissons aux formes variées réalisées à partir de différents matériaux, au gré de l'imagination des créateurs inspirés, de malles aux trésors, cavernes jonchées d'algues dégoulinantes ou autres bateaux Fantôme, ils ont pu admirer les divers jeux de lumières qui les animaient, baignés par le chant des vagues.

3 «Un univers digne de Jules Verne », « des décors un peu factices », « Bof »... Si les adultes demeurent quelque peu critiques, les enfants se sont complu dans cet immense espace de jeu et de rêve.

\section{Christian Bozon : « Sphère transparente avec impression de poissons »}

L'objectif était de réaliser des installations qui traitent du monde marin, sans utilisation de l'eau. Je l'ai alors figurée au moyen de plastique transparent. J'ai confectionné une bulle demi-sphérique, sur laquelle ont été imprimés des poissons bleus. Je désirais, qu'entrant dans la sphère, on sente profondeur, mystère, silence, oppression, comme lorsque l'on est sous l'eau. La systématique du poisson confère, de surcroît, un effet de vertige, de dynamisme aussi - mon thème d'étude actuel ! Ce projet a nécessité la mise en oeuvre de moyens importants et les effets d'éclairage ont été bien réalisés, dans le sens de ce que je voulais obtenir. J'ai été très heureux d'y participer! 


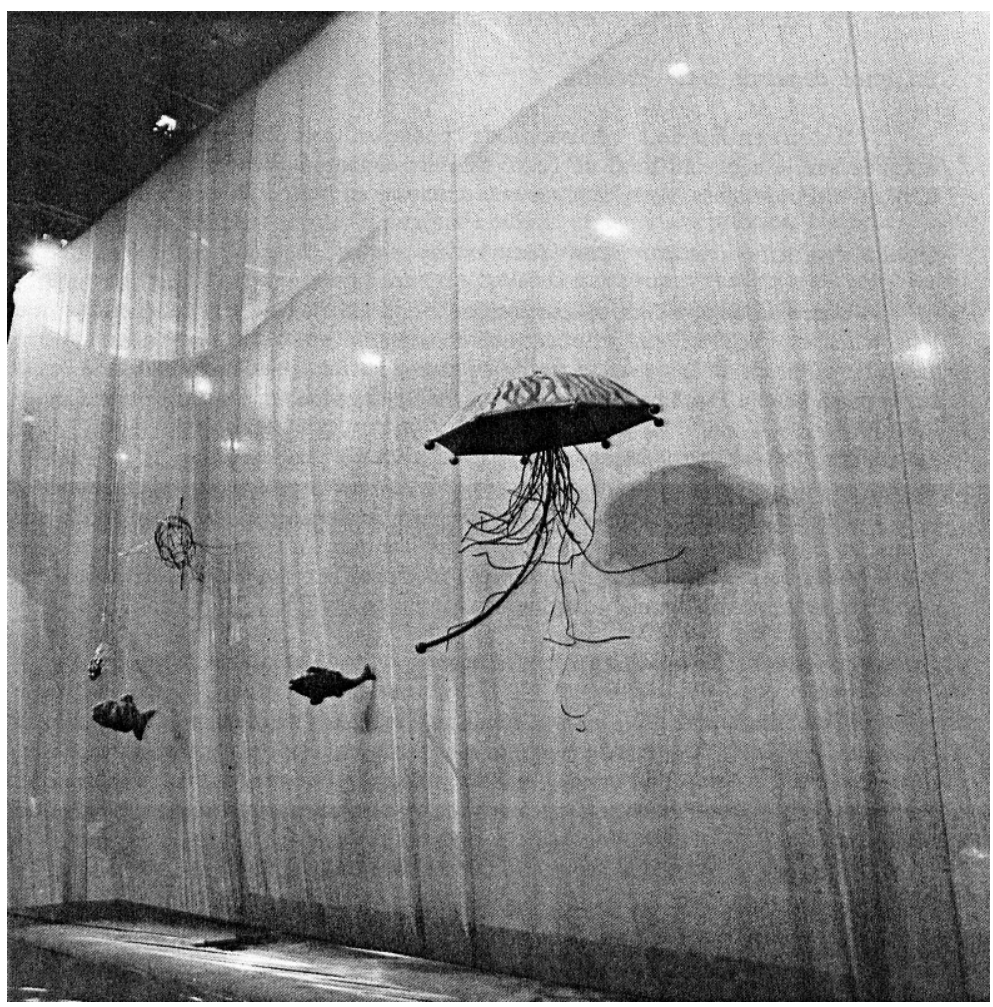

\section{Valérie Goy : « bateau fantôme »} Caralpe a assuré la coordination de toutes les opérations : passage dans les écoles participantes, contacts avec les étudiants des beaux arts, réunion et agencement des projets. C'est à lui que j'ai eu le plus souvent à faire, ainsi qu'à l'équipe technique de l'espace. Ce travail n'était pas très évident à réaliser... je suis globalement satisfaite du résultat

6 Quel a été ton rôle?

7 - J'ai réalisé la sculpture « le bateau fantôme ».

8 En quoi consiste cette création?

9 - Il s'agit en fait de la réalisation de l'image en trois dimensions d'une barque échouée sur le sable au fond de l'eau. Elle est constituée de bandes de plastique transparent, imprimées, agraphées sur une armature en bois.

10 Quelle évolution ont suivi tes idées et ton travail?

11 - L'idée de départ était un phénomène d'optique : on devait voir le bateau de loin, mais, en s'approchant, en pénétrant dans les décors, cette image devrait être annihilée au profit de la sensation tactile du plastique froid et brillant (image de l'eau) sur la peau. Bateau fantôme... parce qu'intouchable, impalpable, porteur de rêve...

12 Le résultat t'a-t-il satisfaite?

13 - Pas entièrement. La raison en est simple : le dessin a été effectué bande par bande, et je n'ai pu en surveiller l'évolution (difficile avec un dessin de deux mètres de haut sur 
des bandes d'une longueur de cinq mètres!). Au moment du montage, des décalages sont apparus, rendant l'arrière du bateau peu visible.

14 Qu'est-ce que cette expérience t'a apporté?

15 - C'est la première fois que je participe à une réalisation de cette envergure. J'ai été ravie de réaliser une de mes maquettes à grande échelle... C'est fort enrichissant. Contraintes à respecter... de temps, bien sûr, mais aussi de sécurité. Le plastique par exemple était en matière spéciale "pare-feu », l'armature, trop légère, a dû être renforcée... etc.

16 Il est aussi bien agréable de ne pas avoir de problème financier, l'espace Planoise ayant fourni tous les matériaux.

17 L'espace Planoise?

18 - Je souhaite qu'il continue sur cette lancée, c'est-à-dire la promotion de jeunes, de très jeunes artistes. Cest ce qui fait vivre un quartier, une ville... C'est dynamisant ! 